$$
25 \text { Research Square }
$$

\title{
Suicidal Ideation and Risk Reduction Associated with Participation in a Therapist-Supported Digital Mental Health Intervention
}

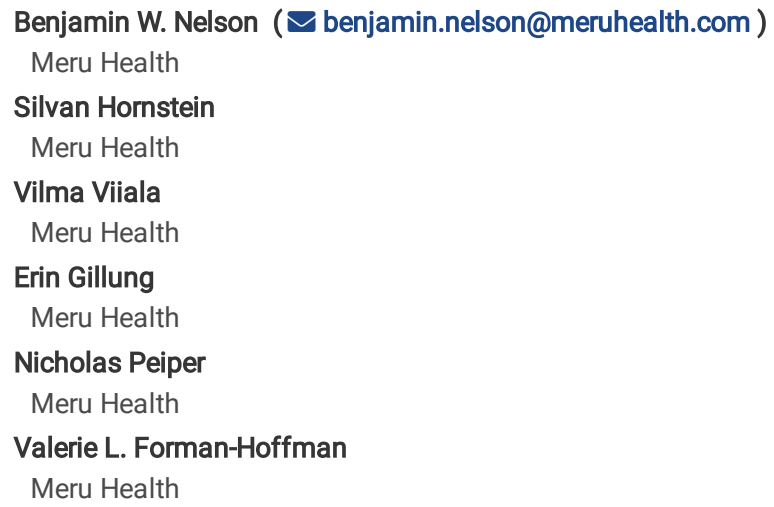




\section{Abstract \\ Background}

Suicide is a significant public health concern with increasing prevalence. Novel interventions that reduce stigma and increase accessibility, such as therapistsupported digital mental health interventions, are urgently needed.

\section{Methods}

This preregistered retrospective cohort, single-arm, and intent-to-treat study with 778 patients examined suicidal ideation (SI) trajectories using multilevel models during and up to 6-months after an 12-week therapist-supported digital mental health intervention (Meru Health Program [MHP]) as assessed by the ninth item of the Patient Health Questionnaire-9 (PHQ-9). Estimates of associated suicide attempts and deaths by suicide were calculated using published data linking PHQ-9-assessed SI to records of suicide attempts and deaths by suicide.

\section{Results}

MHP participants reporting SI "not at all" significantly increased between baseline and end-of-treatment (78.02-91.00\%). Effect sizes of SI changes between baseline and end-of-treatment, 3-month, and 6-month follow-ups were $0.33(95 \% \mathrm{Cl}=0.27-0.38), 0.32(95 \% \mathrm{Cl}=0.27-0.38)$, and $0.32(95 \% \mathrm{Cl}=0.27-0.438)$, respectively. Results also indicated an estimated $30.49 \%$ reduction $(95 \% \mathrm{Cl}=25.15 \%-35.13 \%)$ in suicide attempts and death by suicide across treatment.

\section{Conclusion}

This real-world study provides preliminary evidence that participants of the MHP show significant reductions in SI and estimated suicide attempts and deaths by suicide across treatment that are maintained 6-months following treatment. The next steps are to conduct a randomized control trial to confirm these results.

\section{Introduction}

Suicide is a significant global health concern (1) that is a leading cause of death in the United States. In 2019, nearly 50,000 died by suicide, representing about one death every 11 minutes (2). Unfortunately, there has been little improvement in the prevention of suicidal thoughts and behaviors over the past 50 years $(3,4)$. This is particularly concerning given that recent data indicate that suicidal behaviors and mortality may be on the rise (5-9). In addition to the human cost of suicide attempts and death by suicide, there are significant secondary societal and economic impacts, which totaled \$93.5 billion dollars in the United States in 2013 (10). Increasing rates of suicidal behaviors, significant barriers to treatment, and insufficient number of mental healthcare providers (11) in traditional therapeutic settings demonstrate the need for scalable mental health treatments that have the ability to reduce suicidality and associated costs.

It is estimated that $4.8 \%$ of the United States population reported past-year serious suicidal ideation (SI) in 2019 (12), while the global lifetime prevalence of SI is estimated to be $9.2 \%$ (13). Importantly, SI is a strong predictor of future suicide behaviors (14), such that an estimated $12.5 \%$ (12) to $29 \%$ (14) of those with $\mathrm{SI}$ end up attempting to die by suicide. Risk for SI is not evenly distributed across the population and varies by demographic and clinical factors. For example, females experience SI at higher rates than their male counterparts $(5,13,15)$, while LBGTQ individuals have higher rates than their heteronormative peers $(16$, 17). Furthermore, SI is stratified by age, such that it decreases throughout the lifespan $(13,15)$, as well as by race and ethnicity, such that minority groups experience higher rates of SI as compared to Caucasian individuals (18). Lastly, mental health disorders significantly increase risk for self-injurious thoughts and behaviors (SITB) $(14,19)$, with SI being a common symptom of major depressive disorder that impacts an estimated 17 million US adults (20).

The Patient Health Questionnaire-9 (PHQ-9) is a commonly used self-report questionnaire to assess depressive symptoms within the past two weeks. The 9th item evaluates SITB by asking, "In the last 2 weeks, how often have you been bothered by thoughts that you would be better off dead, or of hurting yourself," and is frequently used to screen for depression and suicide risk. This item is a robust predictor of suicide attempts and death by suicide among primary care and mental health outpatients (21-26), although some research indicates that this item may not be a sufficient screen for SI (27-29). Specifically, these studies have identified that compared to those without SI, those experiencing almost daily SI are 5-8 times more likely to attempt suicide and 3-11 times more likely to die by suicide within 30 days, while they are 2-4 times more likely to attempt suicide and 2-6 times more likely to die by suicide within a year. Strikingly, it is estimated that only $44 \%$ of people experiencing SI and $61 \%$ of those that have attempted suicide seek mental health treatment $(15,18)$. It has been proposed that these low rates of treatment uptake in general are likely due to various barriers to treatment, including not knowing where to seek treatment, inability to get an appointment, treatment costs, transportation, and scheduling issues (30). Therefore, there is a need for novel interventions that reduce barriers to treatment, decrease costs, and increase scalability to reduce SI, suicide attempts, and suicide-related morbidity and mortality.

Digital mental health (DMH) interventions offer one possible solution to address rising mental health complications. Prior research has repeatedly demonstrated the efficacy of these types of interventions across various disorders $(31,32)$. DMH interventions also provide one avenue for scalability by lowering the barriers to treatment in order to reach larger proportions of the populations $(15,18)$, including treatment access in a more cost-effective manner (33), stigma, and ameliorating expected shortages of behavioral health providers $(11,34,35)$. Currently, nascent research indicates that these interventions may be useful in reducing SITB (36-40), yet there is a lack of research indicating whether DMH interventions are associated with reductions not only in SI, but also estimated suicide attempts and death by suicide. This retrospective cohort intent-to-treat (ITT) study, preregistered on Open Science Framework (https://osf.io/eug8w/) with open code, was devised to examine associations between participation in the Meru Health Program (MHP), an evidence-based 
digital mental health intervention, and associated changes in SI across the course of treatment. Furthermore, this study will estimate reductions in suicide attempts and deaths by suicide over the course of treatment and through the follow-up assessments based on recent data (22). First, we hypothesized that treatment week would be negatively associated with SI, with significant reductions in SI from pre-treatment to post-treatment and both 3- and 6-month followups. Second, we hypothesized that there would be significant reductions in estimated suicide attempts and estimated deaths by suicide from pre-treatment to post-treatment and both 3- and 6-month follow-ups.

\section{Methods And Materials}

\section{Participants.}

The present study included patients treated with the MHP, an evidence-based therapist-supported DMH intervention. In the United States, Meru Health operates a professional corporation in California and Florida and has been treating patients since 2018. In the present study, all data came from recruited participants in the United States who started the program on or after January 1, 2020 and an end date on or before December 1, 2020. We used June 1, 2021 as a cut-off to allow for inclusion of patients able to complete the 12-week treatment program and have a 6-month follow-up in our dataset (i.e., time since December 1 , 2020). Participants were 778 patients, aged 19-63 (see Table 1).

Table 1

Meru Health Program Participant Demographic and Clinical Characteristics

\begin{tabular}{|c|c|c|c|}
\hline Variable & $\mathbf{N}$ & Percentage & Mean (SD), Range \\
\hline Age & 778 & & 40 (11.2), 19-82 \\
\hline \multicolumn{4}{|l|}{ Sex } \\
\hline Female & 600 & $77.12 \%$ & \\
\hline Male & 177 & $22.75 \%$ & \\
\hline Other & 1 & $0.13 \%$ & \\
\hline Baseline PHQ-8 Severity & 218 & & $11.1(5.9)$ \\
\hline Less than Mild & 117 & $15.04 \%$ & \\
\hline Mild & 222 & $28.53 \%$ & \\
\hline Moderate & 187 & $24.04 \%$ & \\
\hline Moderately Severe & 182 & $23.39 \%$ & \\
\hline Severe & 70 & $9.00 \%$ & \\
\hline \multicolumn{4}{|l|}{ MDEs } \\
\hline None & 376 & $48.33 \%$ & \\
\hline First & 114 & $14.65 \%$ & \\
\hline Recurrent & 288 & $37.02 \%$ & \\
\hline \multicolumn{4}{|c|}{ Taking Psychiatric Medication } \\
\hline Yes & 334 & $44.22 \%$ & \\
\hline No & 434 & $55.78 \%$ & \\
\hline \multicolumn{4}{|l|}{ Lifetime Suicide Attempt } \\
\hline Yes & 35 & $4.50 \%$ & \\
\hline No & 743 & $95.50 \%$ & \\
\hline \multicolumn{4}{|c|}{ Lifetime Psychiatric Hospitalization } \\
\hline Yes & 39 & $5.01 \%$ & \\
\hline No & 739 & $94.99 \%$ & \\
\hline \multicolumn{4}{|c|}{ Lifetime History of Major Traumatic Event Exposure } \\
\hline Yes & 327 & $42.03 \%$ & \\
\hline No & 435 & $55.91 \%$ & \\
\hline Unknown & 16 & $2.06 \%$ & \\
\hline \multicolumn{4}{|c|}{ Notes: MDE = Major Depressive Episode; $\mathrm{PHQ}=$ Patient Health Questionnaire } \\
\hline
\end{tabular}




\section{Recruitment.}

Participants entered the MHP via referrals from employee assistance programs or via their healthcare providers. All enrolled patients signed informed consent to participate and to have their collected and deidentified data used for research purposes. Inclusion/exclusion criteria of the MHP required patients to have at least mild levels of depression, anxiety, or burnout, own a smartphone, and not have an active substance use disorder, severe active suicidal ideation with a specific plan, severe active self-harm, or a history of psychosis or mania.

All patients enrolled signed informed consent to participate and have their collected, de-identified data used for research purposes. Data collected as part of care is stored in Health Insurance Portability and Accountability Act-compliant electronic medical records that includes protected health information. All data are encrypted in transit, and at rest. Institutional review board exemption for this analysis was obtained from the Pearl Institutional Review Board (\#21-Meru113) for analyses of previously collected and de-identified data.

\section{Meru Health Program (MHP) Treatment.}

After the informed consent procedure, patients were enrolled in the MHP. Created in 2017, the MHP has been described in detail in prior publications (41, 42). In sum, the MHP is composed of several different evidence-based components or processes of evidence-based therapies delivered via a smartphone app. The program is self-guided but incorporates a stepped and continuous care model that includes daily interaction with a dedicated, licensed clinical therapist and a medical doctor and psychiatrist available for consultation as needed. The program lasts 12 weeks and contains components of Cognitive Behavioral Therapy (43), Behavioral Activation Therapy (44), and Mindfulness-Based Stress Reduction (45), and Mindfulness-Based Cognitive Therapy (46), sleep therapy (47), nutritional psychiatry components (48), heart rate variability biofeedback (49).

Prior to the start of the MHP, participants are trained on how to use the app, including how to participate in the anonymous group interaction and how to communicate with their assigned therapist via chat or phone/video calls. Each week of the program begins with an introductory video that gives the patient an overview of the topics covered that week. Patients are prompted to complete various practices, mostly CBT exercises and journal prompts, as well as short audio-guided mindfulness meditation exercises on a daily or almost daily basis. Daily content and practices range from 5-15 minutes, except for the first day of each week, in which the weekly psychoeducation video lessons extend the content to a maximum of 25 minutes.

A licensed therapist (employed by Meru Health) provides support to participants via messaging (and less frequently, phone or video calls) as needed, and reviews practice logs using a provider "dashboard" and electronic medical records that detail individual progress (including participant engagement and patient-reported outcomes to date). In total, therapists allocate approximately 10-20 minutes (on average) per week per participant. Interaction between therapist and participant can be initiated via either party.

As a safety measure, therapists conduct a phone-based protocol assessment for any participants that show signs of mental deterioration during the intervention. In case of an emergency, such as having SI with intent to act or onset of psychotic symptoms, the intervention includes a written action plan for declining mental health, which all participants are required to review with their therapist prior to engaging with the intervention. In these situations, the care coordination-therapist team at Meru Health will help connect the patient to immediate and local care outside of the program, however, a psychiatrist employed by Meru Health is available for consultation in these situations as well.

Patients complete the MHP as a cohort of typically 8-15 patients. As such, cohorts can interact anonymously when sharing their practice experiences, such as providing and receiving support and feedback on their experiences as they navigate the MHP. Direct communication between participants, however, is not allowed. Instead, participants can post anonymous reflections on practices and lessons to the chat discussion board, to which their therapist can respond freely, and to which other group members can respond with pre-written empathy statements and/or emoticons.

Measures. All measures examined in this study were collected in the MHP app at baseline (before the start of the MHP), biweekly during the MHP including at end-of-treatment, and via email at 3- and 6-month post-treatment.

Patient Health Questionnaire- (PHQ-9). Participants completed the PHQ-9 in order to calculate PHQ-8 depressive symptoms and to assess SI with the 9th item. The PHQ-8 is comprised of all PHQ-9 items, except for the 9th item on $\mathrm{SI}$, and is a list of eight depressive symptoms with response options ranging from 0 (not at all) to 3 (nearly every day). Each symptom is assessed with the stem question, "Over the last 2 weeks, how often have you been bothered by any of the following problems?" The PHQ-9 is a widely used instrument used to screen for depression (50). We used the first 8 items of the PHQ-9 to calculate the PHQ-8, which assessed purely depressive symptoms without the last PHQ-9 item that assesses SI (51). We coded treatment baseline PHQ-8 symptoms using categories established for the PHQ-9 with the 9th item removed as None/Minimal (0-4), Mild (5-9), Moderate (10-14), Moderately Severe (15-19), and Severe $(20-24)$ to assess baseline depression severity, with knowledge that this method could lead to a slightly lower proportion of patients categorized as having moderately severe or severe depression (51).

The primary outcome of interest is the last item of the PHQ-9 to assess suicidal ideation. This item asks whether participants have experienced, "Thoughts that you would be better off dead, or thoughts of hurting yourself in some way?" on a scale from 0- not at all, 1- Several days, 2- More than half the days, 3Nearly every day.

Calculation of Reduction in Lives Lost. We used risk data from Rossom et al. (2017) (23) to calculate estimated reductions in suicide attempts and death by suicide. Based on these findings for 0 (not at all) there is a $0.40 \%$ of suicide attempt and $0.03 \%$ of suicide death risk, 1 (several days) there is a $1.60 \%$ of suicide attempt and $0.12 \%$ of suicide death risk, 2 (more than half the days) there is a $2.80 \%$ of suicide attempt and $0.21 \%$ of suicide death risk, and for 3 (nearly every day) there is a $4.00 \%$ of suicide attempt and $0.30 \%$ for suicide death risk. 
Covariates. Participant age, sex, program engagement as measured by the number of days active each two week period during the 12 week program, severity category of PHQ-8 assessed depressive symptoms, number of self-reported lifetime major depressive episodes (none, first episode, or recurrent), lifetime suicide attempts (self-reported), lifetime prior psychiatric hospitalization (self-reported), lifetime exposure to a major traumatic event (self-reported), and current psychotropic medication use (self-reported) were used as covariates.

\section{Statistical Analysis.}

All statistical analyses were conducted with RStudio, Version 1.3.959. The study was preregistered on Open Science Framework (https://osf.io/eug8w/). Statistical significance was defined using $95 \%$ confidence intervals and $p$-values. Exploratory analyses including histograms as well as skew and kurtosis statistics were run for each variable to check for normality and any variable that then had a skew of +/- 2 was log transformed, except for the PHQ-9 item 9 (skew $=3.81$ ). Descriptive statistics (i.e., $\mathrm{n}$ and percentages or mean and standard deviations) were calculated for each patient demographic and clinical variable (see Table 1). Outcome measures were analyzed using an intention-to-treat (ITT) analysis in which all participants with outcome measures at baseline were included, regardless of intervention engagement or attrition. Approximately $12.7 \%$ of data were missing from the final sample (note this study used ITT, so we included all treatment weeks 0-12 and 3- and 6-month follow-up data as missing for participants that dropped out). To assess whether data were missing completely at random (MCAR) we performed a parametric $(p<0.001)$ test using the Naniar package (52). Despite that data were not MCAR, based on recent recommendations $(53,54)$, in order to account for missing data, we performed multiple imputation (10 imputations) using the mice package (55) (see Supplemental Material for missing data by variable and treatment week).

First, we examined the impact of treatment week on SI by conducting a multilevel model (MLM) that nested treatment week (Level-1) within individuals (Level2) across a linear model and Poisson and negative binomial models to account for the skewed distribution of PHQ-9 Item 9 response (skew=3.81). We used used the Ime4 package (56) for linear and negative binomial models and the glmmTMB package (57) for the Poisson model. Fixed effects including covariates were tested at the level of participants (Level-2). This statistical approach accounts for dependency within participants and introduces less bias due to missing data compared to traditional statistical analyses, such as repeated measures of analysis of variance (58-60). We tested concurrent associations between treatment week and SI during the same week (Level-1).

Second, we used ggstatsplot package (61) to conduct a nonparametric Friedman Test, an alternative to a repeated measures ANOVA for nonnormal data, to determine whether there were significant reductions in SI between pre-treatment and post-treatment, 3-month, and 6-month follow-ups. We then used the rstatix package (62) to conduct nonparametric paired samples Wilcoxon Test contrasts that were corrected for multiple comparisons using the Holm Method (63) to determine whether there was a significant reduction in between pre-treatment and post-treatment, 3-month, and 6-month follow-ups.

Third, we performed frequency statistics on the response options of the last item of the PHQ-9 at pre-treatment and post-treatment to calculate count and percentage of participants in each response option group. We then used suicide attempt and death by suicide data from Rossom et al., (2017) (23) to calculate estimated suicide attempts and death by suicide at pre-treatment, post-treatment, 3-month, and 6-month follow-ups. The percent reduction in suicide attempts and death by suicide at post-treatment timepoints was calculated with the following equation: (pre-treatment percent - post-treatment percent)/pretreatment percent ${ }^{\star} 100$. We used the equation $1 /$ (pre-treatment percent-post-treatment percent) to calculate the number needed to treat (NNT) for both suicide attempts and deaths by suicide outcomes.

\section{Results}

\section{Demographic and Clinical Characteristics}

Table 1 presents demographic and clinical characteristics for patients who entered the MHP in 2020 ( $N=778)$. The majority of patients were female (77.12\%) with an average age of 40 . The mean baseline PHQ-8 was 11.1, which falls into the moderate range of symptom severity. Just under half of the sample (44.22\%) reported taking psychiatric medication, while $42.03 \%$ reported a past traumatic event exposure. Finally, most participants (95.22\%) had never attempted suicide or had a psychiatric hospitalization (94.99\%).

\section{Changes In Suicidal Ideation}

The proportion of MHP participants reporting SI "not at all" significantly increased between baseline (pre-MHP) and end-of-treatment (78.02-91.00\%, see Table 2). Conversely, there was a significant decline in reported suicidal ideation during treatment that was maintained at 3-and 6-month follow-ups (Figure 1). Effect sizes of SI changes between baseline and end-of-treatment, baseline and 3-month, and baseline and 6-month follow-ups were Hedge's g=0.33 $(95 \% \mathrm{Cl}=0.27-0.38)$, Hedge's $\mathrm{g}=0.32(95 \% \mathrm{Cl}=0.27-0.38)$, and Hedge's $\mathrm{g}=0.32(95 \% \mathrm{Cl}=0.27-0.38)$, respectively, indicating a moderate effect size. The significant declines in SI remained after adjusting for demographic and clinical characteristics across linear $(\beta=-0.110, p<0.001)$, Poisson (log mean $=-0.158, p<0.001)$, and negative binomial (log-mean $=-0.158, p<0.001$ ) models (Table 3 ). The trajectories of SI by depressive symptom severity appeared to be steepest in the first few weeks of treatment and then tapered off towards the end-of-treatment and continued to be stable over the 3-and 6-month follow-up assessments for each of the severity groups (see Figure 2 for individual and pre-treatment symptom severity group trajectories). Individual participant depressive symptom trajectories are displayed in Supplementary Figure S1. 
Table 2

Suicidal Ideation Across Meru Health Program Treatment and Follow-Up

\begin{tabular}{|llll|}
\hline Suicidal Ideation & Baseline Frequency (\%) & $\begin{array}{l}\text { End-of-Treatment } \\
\text { Frequency (\%) }\end{array}$ & $\begin{array}{l}3 \text { Month } \\
\text { Follow-Up } \\
\text { Frequency (\%) }\end{array}$ \\
\hline 0 (not at all) & $607(78.02 \%)$ & $708(91.00 \%)$ & $717(92.16 \%)$ \\
\hline 1 (several days) & $127(16.32 \%)$ & $63(8.10 \%)$ & $58(7.46 \%)$ \\
\hline 2 (more than half the days) & $33(4.24 \%)$ & $6(0.77 \%)$ & $2(0.26 \%)$ \\
\hline 3 (nearly every day) & $11(1.41 \%)$ & $1(0.13 \%)$ & $1(0.13 \%)$ \\
\hline $\begin{array}{l}\text { Mean (SD) } \\
\text { Effect Size }\end{array}$ & $0.29(0.61)$ & $0.10(0.34)$ & $0.08(0.30)$ \\
\hline $\begin{array}{l}\text { Notes: SD=standard deviation. Suicidal ideation over the last 2 weeks is measured by the ninth item of the Patient Health Questionnaire-9 item (PHQ-9), } \\
\text { with } 0=\text { not at all, } 1=\text { several days, 2=more than half the days, and 3=nearly every day. }\end{array}$ & $0.34(0.27 .0 .41)$ \\
\hline
\end{tabular}


Table 3

Adjusted Associations of Changes in Suicidal Ideation Across Meru Health Program Treatment

\begin{tabular}{|c|c|c|c|c|c|c|c|c|c|c|c|}
\hline \multirow[b]{2}{*}{ Predictors } & \multicolumn{4}{|l|}{ Linear Model } & \multicolumn{4}{|c|}{ Poisson Model } & \multicolumn{3}{|c|}{ Negative Binomial Model } \\
\hline & $\begin{array}{l}\text { Standardized } \\
\text { Beta }\end{array}$ & $\begin{array}{l}\text { Standardized } \\
\text { SE }\end{array}$ & $\begin{array}{l}\text { Standardized } \\
\mathrm{Cl}\end{array}$ & $\begin{array}{l}P \text { - } \\
\text { Value }\end{array}$ & $\begin{array}{l}\text { Log- } \\
\text { Mean }\end{array}$ & $S E$ & $\mathrm{Cl}$ & $\begin{array}{l}P \text { - } \\
\text { Value }\end{array}$ & $\begin{array}{l}\text { Log- } \\
\text { Mean }\end{array}$ & $S E$ & $\mathrm{Cl}$ \\
\hline (Intercept) & -0.321 & 0.062 & $\begin{array}{l}-0.442- \\
-0.201\end{array}$ & $<0.001$ & -4.197 & 0.481 & $\begin{array}{l}-5.140- \\
-3.255\end{array}$ & $<0.001$ & -4.197 & 0.560 & $\begin{array}{l}-5 \\
-3\end{array}$ \\
\hline $\begin{array}{l}\text { Treatment } \\
\text { Week }\end{array}$ & -0.110 & 0.013 & $\begin{array}{l}-0.137- \\
-0.084\end{array}$ & $<0.001$ & -0.158 & 0.022 & $\begin{array}{l}-0.201- \\
-0.114\end{array}$ & $<0.001$ & -0.158 & 0.013 & $\begin{array}{l}-0 \\
-0\end{array}$ \\
\hline Sex-Male & 0.087 & 0.055 & $\begin{array}{l}-0.020- \\
0.194\end{array}$ & 0.111 & 0.259 & 0.171 & $\begin{array}{l}-0.076- \\
0.594\end{array}$ & 0.130 & 0.259 & 0.177 & -0 . \\
\hline \multirow[t]{2}{*}{ Sex-Other } & -0.620 & 0.631 & $\begin{array}{l}-1.857- \\
0.617\end{array}$ & 0.326 & -15.901 & 2063.644 & $-4060.570-$ & 0.994 & -22.229 & 65819.200 & $-1:$ \\
\hline & & & & & & & 4028.767 & & & & 12 \\
\hline Age & -0.045 & 0.023 & $\begin{array}{l}-0.090- \\
0.001\end{array}$ & 0.054 & -0.016 & 0.006 & $\begin{array}{l}-0.028- \\
-0.003\end{array}$ & 0.014 & -0.016 & 0.007 & $\begin{array}{l}-0 . \\
-0\end{array}$ \\
\hline $\begin{array}{l}\text { Average Days } \\
\text { Active Weekly }\end{array}$ & -0.098 & 0.012 & $\begin{array}{l}-0.122- \\
-0.075\end{array}$ & $<0.001$ & -0.047 & 0.010 & $\begin{array}{l}-0.066- \\
-0.028\end{array}$ & $<0.001$ & -0.047 & 0.010 & $\begin{array}{l}-0 \\
-0\end{array}$ \\
\hline Single MDE & 0.121 & 0.069 & $\begin{array}{l}-0.014- \\
0.256\end{array}$ & 0.078 & 0.472 & 0.233 & $\begin{array}{l}0.014- \\
0.929\end{array}$ & 0.043 & 0.472 & 0.249 & -0 . \\
\hline Recurrent MDE & 0.205 & 0.055 & $\begin{array}{l}0.097- \\
0.312\end{array}$ & $<0.001$ & 0.871 & 0.176 & $\begin{array}{l}0.527- \\
1.216\end{array}$ & $<0.001$ & 0.871 & 0.185 & 0. \\
\hline $\begin{array}{l}\text { Lifetime } \\
\text { Psychiatric } \\
\text { Hospitalization- } \\
\text { Yes }\end{array}$ & 0.433 & 0.116 & $\begin{array}{l}0.206- \\
0.660\end{array}$ & $<0.001$ & 0.563 & 0.290 & $\begin{array}{l}-0.006- \\
1.132\end{array}$ & 0.053 & 0.563 & 0.290 & -0 . \\
\hline $\begin{array}{l}\text { Lifetime } \\
\text { Suicide } \\
\text { Attempt-Yes }\end{array}$ & -0.005 & 0.123 & $\begin{array}{l}-0.245- \\
0.235\end{array}$ & 0.967 & -0.090 & 0.314 & $\begin{array}{l}-0.706- \\
0.526\end{array}$ & 0.774 & -0.090 & 0.316 & -0 . \\
\hline $\begin{array}{l}\text { Lifetime Major } \\
\text { Traumatic } \\
\text { Event } \\
\text { Exposure- } \\
\text { Unknown }\end{array}$ & -0.018 & 0.162 & $\begin{array}{l}-0.337- \\
0.300\end{array}$ & 0.910 & 0.151 & 0.427 & $\begin{array}{l}-0.687- \\
0.988\end{array}$ & 0.724 & 0.151 & 0.434 & -0 . \\
\hline $\begin{array}{l}\text { Lifetime Major } \\
\text { Traumatic } \\
\text { Event } \\
\text { Exposure-Yes }\end{array}$ & -0.015 & 0.048 & $\begin{array}{l}-0.110- \\
0.080\end{array}$ & 0.753 & 0.152 & 0.154 & $\begin{array}{l}-0.149- \\
0.453\end{array}$ & 0.322 & 0.152 & 0.160 & -0 . \\
\hline $\begin{array}{l}\text { Baseline PHQ-8 } \\
\text { Symptom } \\
\text { Severity- Mild }\end{array}$ & 0.012 & 0.068 & $\begin{array}{l}-0.121- \\
0.145\end{array}$ & 0.864 & 1.049 & 0.437 & $\begin{array}{l}0.193- \\
1.905\end{array}$ & 0.016 & 1.049 & 0.533 & 0.1 \\
\hline $\begin{array}{l}\text { Baseline PHQ-8 } \\
\text { Symptom } \\
\text { Severity- } \\
\text { Moderate }\end{array}$ & 0.131 & 0.072 & $\begin{array}{l}-0.010- \\
0.272\end{array}$ & 0.068 & 2.010 & 0.424 & $\begin{array}{l}1.178- \\
2.841\end{array}$ & $<0.001$ & 2.010 & 0.515 & 1.1 \\
\hline $\begin{array}{l}\text { Baseline PHQ-8 } \\
\text { Symptom } \\
\text { Severity- } \\
\text { Moderately } \\
\text { Severe }\end{array}$ & 0.420 & 0.075 & $\begin{array}{l}0.272- \\
0.567\end{array}$ & $<0.001$ & 2.797 & 0.420 & $\begin{array}{l}1.975- \\
3.620\end{array}$ & $<0.001$ & 2.797 & 0.509 & 1.1 \\
\hline $\begin{array}{l}\text { Baseline PHQ-8 } \\
\text { Symptom } \\
\text { Severity- Severe }\end{array}$ & 0.579 & 0.099 & $\begin{array}{l}0.386- \\
0.773\end{array}$ & $<0.001$ & 3.210 & 0.441 & $\begin{array}{c}2.344- \\
4.075\end{array}$ & $<0.001$ & 3.210 & 0.526 & 2. \\
\hline $\begin{array}{l}\text { Taking } \\
\text { Psychotropic } \\
\text { Medication }\end{array}$ & 0.022 & 0.034 & $\begin{array}{l}-0.045- \\
0.089\end{array}$ & 0.519 & 0.005 & 0.114 & $\begin{array}{l}-0.219- \\
0.229\end{array}$ & 0.967 & 0.005 & 0.118 & -0 . \\
\hline $\begin{array}{l}\text { Marginal } \mathrm{R}^{2} / \\
\text { Conditional } \mathrm{R}^{2}\end{array}$ & $0.108 / 0.536$ & & & & $0.289 /$ & 540 & & & $0.313 /$ & 556 & \\
\hline
\end{tabular}


Significant correlates of change in SI across all models included average days of weekly activity (-), having a history of recurrent major depressive episodes versus no lifetime major depressive episodes (+), and having either moderately severe or severe baseline depressive symptoms versus less than mild depressive symptoms (+). Other significant correlates included age (- in Poisson and negative binomial models only), having a single episode of major depressive episode versus no lifetime major depressive episodes (+ in the Poisson model only), having a history of a psychiatric hospitalization (+ in the linear model only), and mild or moderate depressive symptom severity versus less than mild depressive symptoms (+ in Poisson and negative binomial models only).

\section{Estimates Of Change In Suicide Attempts And Deaths}

Suicide attempt estimates fell from $0.75-0.52 \%$ from pre- to post-treatment and further declined to $0.50 \%$ and $0.49 \%$ at 3 - and 6 -month follow-up. For death by suicide, estimates reduced from $0.033-0.003 \%$ between pre-and post-treatment that were maintained at 3-and 6 -month follow-ups (0.003\% and $0.0003 \%$, respectively). These represent a $30.49 \%$ reduction $(95 \% \mathrm{Cl}=25.15 \%-35.13 \%)$ in estimates of both suicide attempts and death by suicide between pre- and posttreatment. Extrapolating findings to number needed to treat (NNT) estimates for end-of-treatment, analyses revealed that one suicide attempt would be prevented for every 438 participants enrolled in the MHP and one death by suicide would be prevented for every 5841 participants enrolled in the MHP.

\section{Discussion}

The current preregistered retrospective cohort, single arm, ITT study was devised to investigate whether SI reduced during and following participation in the MHP among 778 patients. In addition, the study aimed to estimate reductions in suicide attempts and deaths by suicide among this sample. Overall, this study shows preliminary effectiveness and feasibility of improving SI among patients who participate in a therapist-supported, evidence-based program delivered via a smartphone app.

Our preregistered a priori hypotheses were supported by our findings. First, across linear, Poisson, and negative binomial MLM models, treatment week was associated with significant decreases in SI across treatment over and above pre-treatment depression symptom severity as well as relevant demographic and clinical characteristics, indicating a robust treatment associated reduction in symptoms across patients. In addition to treatment week effects, these models revealed that a history of MDE, particularly recurrent history of MDE, was associated with higher SI across treatment and that higher pre-treatment depression symptom severity was associated with greater SI as would be expected. In addition, in Poisson and negative binomial models, older age was associated with lower SI, which coincides with findings that SI tends to have a negative association with age (64). The number of days patients engaged with therapy each week was also associated with lower rates of $\mathrm{SI}$, which coincides with recent research indicating that twice vs once weekly therapy sessions is more effective at reducing depressive symptoms and attrition (65). This finding suggests mHealth interventions that prioritize frequent practice of psychotherapy skills may be particularly useful in lowering symptoms of depression, including SI. In contrast to expected results, a history of suicide attempt and psychiatric hospitalization were not significantly associated with SI, except for the latter in linear models, which did not fit the data as well as Poisson and negative binomial models (see Table S1).

Results also indicated that there was a significant overall reduction in SI from pre-treatment to post-treatment, which was maintained at both 3- and 6-month follow-ups, indicating a robust and long-lasting association between treatment on SI trajectories across time. Importantly, while SI continued to decrease from post-treatment to 3-and 6-month follow-ups, there was no significant decrease, possibly due to a floor effect. Finally, there was a greater than $30 \%$ decrease in both estimated suicide attempts and deaths by suicide during the 12-week MHP intervention. The estimated NNT of 438 and 5,841 for attempts and deaths, respectively, suggests that enrollment in the MHP may be a potential suicide prevention strategy.

\section{Limitations And Future Directions}

While this study had a number of significant strengths including a large sample size of patients with a diverse history of psychiatric and clinical characteristics with an ITT study design, the study findings should be interpreted in light of several limitations. Most of these limitations related to the use of real-world data collected as part of continuous improvement of a mHealth intervention. First, due to its availability within the treatment program, our SI measure was the 9th item of the PHQ-9 rather than a validated instrument. Although the 9th item of the PHQ-9 has been shown to be a robust predictor of suicidal behavior in study populations (21-26), some research indicates that this item may not be a sufficient screen for SI (28). Furthermore, the predictive ability of the 9th item of the PHQ-9 may vary by demographic and clinical characteristics (29) so it might be a limited predictor of individual-level suicide (27). Future studies should collect gold-standard assessments of $\operatorname{SITB}(66,67)$. Second, estimated reduction in suicide attempts and death $(23)$ are based on recently published associations between $\mathrm{SI}$ and these outcomes rather than actual data on attempts and deaths by suicide. Future studies that collect longitudinal follow-up data to assess actual rates of suicide attempts and death are needed to better understand these associations. Lastly, this analysis of clinical data collected in a real-world setting precluded the comparison of findings to a control group. Because SI tends to wax and wane, we cannot be sure that patients in our study would not have improved on their own without treatment. Future blinded randomized control trials are required to test the MHP headto-head against other evidence-based in-person and digitally delivered intervention to determine whether these findings hold true as compared to more standard types of care.

\section{Conclusion}

Suicide attempts and death by suicide are significant global health concerns associated not only with the human cost, but also significant secondary societal and economic impacts. There has been little improvement in the prevention of SI in the past 50 years despite SI being a robust predictor of future risk of both suicide attempts and associated deaths. There is a pressing need for novel interventions that reduce barriers to treatment, decrease costs, and increase 
scalability in order to reduce these suicide outcomes. As such, this real-world ITT study indicates that participants of the MHP, an evidence-based stepped care mHealth intervention, show significant reductions in $\mathrm{SI}$, as well as estimates of suicide attempts and deaths by suicide, across treatment that are maintained at 3- and 6-month follow-ups.

\section{Declarations}

\section{Author Contributors}

B.W.N. created the preregistration, ran analyses, and drafted the manuscript. V.F.H. conceived of the study idea. V.F.H., N.P., S.H., E.H., V.V. provided feedback and edits to the manuscript. All authors contributed to the final draft.

\section{Funding Source}

This was an internally funded study. The funder of the study had no role in the study design, data interpretation, or writing of the manuscript. All decisions about the research were taken by the investigative team and were unrestricted.

\section{Consent for Publication}

Not applicable.

\section{Acknowledgements}

We would like to thank the Meru Health Program participants and therapists as well as Meru Health care coordination, operations, and product teams for making this research possible.

\section{Conflicts of Interest}

All authors are employed by Meru Health and receive a salary and stock options from Meru Health. The content is solely the responsibility of the authors and does not necessarily represent the official views of Meru Health, Inc. All decisions about the research were taken by the authors and unrestricted.

\section{Ethics Committee Approval}

This study was deemed exempt from human subjects review by the Pearl Institutional Review Board (21-MERU-113). Informed consent for the participant is collected during treatment intake when accepting the notice of privacy practices. Administrative permissions were not required to access and use the medical records described in your study. We confirm that all methods were performed in accordance with the relevant guidelines and regulations.

\section{Availability of data and materials}

The data would be available from the authors upon reasonable request and with permission of Meru Health provided that the requestor agrees to keep the data confidential.

\section{References}

1. WHO. Suicide [Internet]. World Health Organization. 2019 [cited 2021 Mar 25]. Available from: https://www.who.int/news-room/fact-sheets/detail/suicide

2. CDC. Suicide Fast Facts [Internet]. CDC. 2021 [cited 2021 Mar 22]. Available from: https://www.cdc.gov/suicide/facts/index.html? CDC_AA_refVal=https\%3A\%2F\%2Fwww.cdc.gov\%2Fviolenceprevention\%2Fsuicide\%2Ffastfact.html

3. Franklin JC, Ribeiro JD, Fox KR, Bentley KH, Kleiman EM, Huang X, et al. Risk factors for suicidal thoughts and behaviors: A meta-analysis of 50 years of research. Psychol Bull [Internet]. 2017 Feb;143(2):187-232. Available from: http://dx.doi.org/10.1037/bul0000084

4. Zalsman G, Hawton K, Wasserman D, van Heeringen K, Arensman E, Sarchiapone M, et al. Suicide prevention strategies revisited: 10-year systematic review. Lancet Psychiatry [Internet]. 2016 Jul;3(7):646-59. Available from: http://dx.doi.org/10.1016/S2215-0366(16)30030-X

5. CDC. Web-based Injury Statistics Query and Reporting System (WISQARS) [Internet]. Centers for Disease Control and Prevention. 2020 [cited 2021 Mar 24]. Available from: https://www.cdc.gov/injury/wisqars/?

CDC_AA_refVal=https\%3A\%2F\%2Fwww.cdc.gov\%2Finjury\%2Fwisqars\%2Foverview\%2Fkey_data.html

6. CDC. Suicide rising across the US [Internet]. Centers for Disease Control and Prevention. 2018 [cited 2021 Mar 24]. Available from: https://www.cdc.gov/vitalsigns/suicide/index.html

7. Hedegaard H, Curtin SC, Warner M. Suicide Mortality in the United States, 1999-2019 [Internet]. Centers for Disease Control and Prevention. 2021 [cited 2021 Mar 24]. Available from: https://www.cdc.gov/nchs/products/databriefs/db398.htm

8. Hedegaard H, Curtin SC, Warner M. Suicide Rates in the United States Continue to Increase. NCHS Data Brief [Internet]. 2018 Jun;(309):1-8. Available from: https://www.ncbi.nlm.nih.gov/pubmed/30312151

9. Hedegaard H, Curtin SC, Warner M. Increase in Suicide Mortality in the United States, 1999-2018. NCHS Data Brief [Internet]. 2020 Apr;(362):1-8. Available from: https://www.ncbi.nlm.nih.gov/pubmed/32487287

10. Shepard DS, Gurewich D, Lwin AK, Reed GA Jr, Silverman MM. Suicide and Suicidal Attempts in the United States: Costs and Policy Implications. Suicide Life Threat Behav [Internet]. 2016 Jun;46(3):352-62. Available from: http://dx.doi.org/10.1111/sltb.12225 
11. SAMHSA. National Projections of Supply and Demand for Selected Behavioral Health Practitioners: $2013-2025$ [Internet]. Health Resources and Services Administration. National Center for Health Workforce Analysis. Substance Abuse and Mental Health Services Administration. Office of Policy, Planning, and Innovation. 2016 [cited 2021 Mar 29]. Available from: https://bhw.hrsa.gov/sites/default/files/bureau-health-workforce/data-research/behavioralhealth-2013-2025.pdf

12. SAMHSA. Key substance use and mental health indicators in the United States: Results from the 2019 National Survey on Drug Use and Health (HHS Publication No. PEP20-07-01-001, NSDUH Series H-55) [Internet]. 2020 [cited 2021 Jun 6]. Available from: https://www.google.com/url? q=https://www.samhsa.gov/data/\&sa=D\&source=editors\&ust=1623072354262000\&usg=AOvVaw1gaHShJ-I1ENfzyppOno1n

13. Nock MK, Borges G, Bromet EJ, Alonso J, Angermeyer M, Beautrais A, et al. Cross-national prevalence and risk factors for suicidal ideation, plans and attempts. Br J Psychiatry [Internet]. 2008 Feb;192(2):98-105. Available from: http://dx.doi.org/10.1192/bjp.bp.107.040113

14. Nock MK, Borges G, Bromet EJ, Cha CB, Kessler RC, Lee S. Suicide and suicidal behavior. Epidemiol Rev [Internet]. 2008 Jul 24;30:133-54. Available from: http://dx.doi.org/10.1093/epirev/mxn002

15. Kessler RC, Berglund P, Borges G, Nock M, Wang PS. Trends in suicide ideation, plans, gestures, and attempts in the United States, 1990-1992 to 20012003. JAMA [Internet]. 2005 May 25;293(20):2487-95. Available from: http://dx.doi.org/10.1001/jama.293.20.2487

16. Figueiredo AR, Abreu T. Suicide Among Lgbt Individuals. Eur Psychiatry [Internet]. 2015 Mar [cited 2021 Mar 26];30(S1):1-1. Available from: https://www.cambridge.org/core/journals/european-psychiatry/article/suicide-among-lgbt-individuals/2F8EBDCAA48C66F638D05245A39663DB

17. Ivey-Stephenson AZ, Demissie Z, Crosby AE, Stone DM, Gaylor E, Wilkins N, et al. Suicidal Ideation and Behaviors Among High School Students - Youth Risk Behavior Survey, United States, 2019. MMWR Suppl [Internet]. 2020 Aug 21;69(1):47-55. Available from: http://dx.doi.org/10.15585/mmwr.su6901a6

18. Ahmedani BK, Perron B, Ilgen M, Abdon A, Vaughn M, Epperson M. Suicide thoughts and attempts and psychiatric treatment utilization: informing prevention strategies. Psychiatr Serv [Internet]. 2012 Feb 1;63(2):186-9. Available from: http://dx.doi.org/10.1176/appi.ps.201100159

19. Bertolote JM, Fleischmann A. Suicide and psychiatric diagnosis: a worldwide perspective. World Psychiatry [Internet]. 2002 Oct;1(3):181-5. Available from: https://www.ncbi.nlm.nih.gov/pubmed/16946849

20. NIH. Major Depression [Internet]. NIH. 2019 [cited 2021 Mar 26]. Available from: https://www.nimh.nih.gov/health/statistics/major-depression.shtml

21. Simon GE, Coleman KJ, Rossom RC, Beck A, Oliver M, Johnson E, et al. Risk of suicide attempt and suicide death following completion of the Patient Health Questionnaire depression module in community practice. J Clin Psychiatry [Internet]. 2016 Feb;77(2):221-7. Available from: http://dx.doi.org/10.4088/JCP.15m09776

22. Simon GE, Rutter CM, Peterson D, Oliver M, Whiteside U, Operskalski B, et al. Does response on the PHQ-9 Depression Questionnaire predict subsequent suicide attempt or suicide death? Psychiatr Serv [Internet]. 2013 Dec 1;64(12):1195-202. Available from: http://dx.doi.org/10.1176/appi.ps.201200587

23. Rossom RC, Coleman KJ, Ahmedani BK, Beck A, Johnson E, Oliver M, et al. Suicidal ideation reported on the PHQ9 and risk of suicidal behavior across age groups. J Affect Disord [Internet]. 2017 Jun;215:77-84. Available from: http://dx.doi.org/10.1016/j.jad.2017.03.037

24. Louzon SA, Bossarte R, McCarthy JF, Katz IR. The Clinical Utility of PHQ-9 Item 9 for Suicide Prediction: In Reply. Psychiatr Serv [Internet]. 2016 Sep 1;67(9):1042-3. Available from: http://dx.doi.org/10.1176/appi.ps.670903

25. Louzon SA, Bossarte R, McCarthy JF, Katz IR. Does Suicidal Ideation as Measured by the PHQ-9 Predict Suicide Among VA Patients? Psychiatr Serv [Internet]. 2016 May 1;67(5):517-22. Available from: http://dx.doi.org/10.1176/appi.ps.201500149

26. Yarborough BJH, Stumbo SP, Ahmedani B, Rossom R, Coleman K, Boggs JM, et al. Suicide Behavior Following PHQ-9 Screening Among Individuals With Substance Use Disorders. J Addict Med [Internet]. 2021;15(1):55-60. Available from: http://dx.doi.org/10.1097/ADM.0000000000000696

27. McCusker PJ. The Clinical Utility of PHQ-9 Item 9 for Suicide Prediction. Psychiatr Serv [Internet]. 2016 Sep 1;67(9):1042. Available from: http://dx.doi.org/10.1176/appi.ps.670904

28. Razykov I, Ziegelstein RC, Whooley MA, Thombs BD. The PHQ-9 versus the PHQ-8-is item 9 useful for assessing suicide risk in coronary artery disease patients? Data from the Heart and Soul Study. J Psychosom Res [Internet]. 2012 Sep;73(3):163-8. Available from: http://dx.doi.org/10.1016/j.jpsychores.2012.06.001

29. Na PJ, Yaramala SR, Kim JA, Kim H, Goes FS, Zandi PP, et al. The PHQ-9 Item 9 based screening for suicide risk: a validation study of the Patient Health Questionnaire (PHQ)-9 Item 9 with the Columbia Suicide Severity Rating Scale (C-SSRS). J Affect Disord [Internet]. 2018 May;232:34-40. Available from: http://dx.doi.org/10.1016/j.jad.2018.02.045

30. Andrade LH, Alonso J, Mneimneh Z, Wells JE, Al-Hamzawi A, Borges G, et al. Barriers to mental health treatment: results from the WHO World Mental Health surveys. Psychol Med [Internet]. 2014 Apr;44(6):1303-17. Available from: http://dx.doi.org/10.1017/S0033291713001943

31. Richards D, Richardson T. Computer-based psychological treatments for depression: a systematic review and meta-analysis. Clin Psychol Rev [Internet] 2012 Jun;32(4):329-42. Available from: http://dx.doi.org/10.1016/j.cpr.2012.02.004

32. Kuester A, Niemeyer H, Knaevelsrud C. Internet-based interventions for posttraumatic stress: A meta-analysis of randomized controlled trials. Clin Psychol Rev [Internet]. 2016 Feb;43:1-16. Available from: http://dx.doi.org/10.1016/j.cpr.2015.11.004

33. Meru Health. MERU HEALTH COST SAVINGS WHITE PAPER. 2020.

34. Andrilla CHA, Patterson DG, Garberson LA, Coulthard C, Larson EH. Geographic Variation in the Supply of Selected Behavioral Health Providers. Am J Prev Med [Internet]. 2018 Jun;54(6 Suppl 3):S199-207. Available from: http://dx.doi.org/10.1016/j.amepre.2018.01.004

35. Kaiser Family Foundation. Mental Health Care Health Professional Shortage Areas (HPSAs) [Internet]. Kaiser Family Foundation. 2020 [cited 2021 Mar 29]. Available from: https://www.kff.org/other/state-indicator/mental-health-care-health-professional-shortage-areas-hpsas/?

currentTimeframe=0\&sortModel=\%7B\%22colld\%22:\%22Location\%22,\%22sort\%22:\%22asc\%22\%7D

Page $10 / 13$ 
36. Büscher R, Torok M, Terhorst Y, Sander L. Internet-Based Cognitive Behavioral Therapy to Reduce Suicidal Ideation: A Systematic Review and Metaanalysis. JAMA Netw Open [Internet]. 2020 Apr 1;3(4):e203933. Available from: http://dx.doi.org/10.1001/jamanetworkopen.2020.3933

37. Hetrick SE, Yuen HP, Bailey E, Cox GR, Templer K, Rice SM, et al. Internet-based cognitive behavioural therapy for young people with suicide-related behaviour (Reframe-IT): a randomised controlled trial. Evid Based Ment Health [Internet]. 2017 Aug;20(3):76-82. Available from:

http://dx.doi.org/10.1136/eb-2017-102719

38. Sander LB, Lemor M-L, Van der Sloot RJA, De Jaegere E, Büscher R, Messner E-M, et al. A Systematic Evaluation of Mobile Health Applications for the Prevention of Suicidal Behavior or Non-suicidal Self-injury. Frontiers in Digital Health [Internet]. 2021;3:79. Available from:

https://www.frontiersin.org/article/10.3389/fdgth.2021.689692

39. Büscher R, Beisemann M, Doebler P, Steubl L, Domhardt M, Cuijpers P, et al. Effectiveness of Internet- and Mobile-Based Cognitive Behavioral Therapy to Reduce Suicidal Ideation and Behaviors: Protocol for a Systematic Review and Meta-Analysis of Individual Participant Data. Int J Environ Res Public Health [Internet]. 2020 Jul 17;17(14). Available from: http://dx.doi.org/10.3390/ijerph17145179

40. Sander L, Gerhardinger K, Bailey E, Robinson J, Lin J, Cuijpers P, et al. Suicide risk management in research on internet-based interventions for depression: A synthesis of the current state and recommendations for future research. J Affect Disord [Internet]. 2020 Feb 15;263:676-83. Available from: http://dx.doi.org/10.1016/j.jad.2019.11.045

41. Economides M, Ranta K, Nazander A, Hilgert O, Goldin PR, Raevuori A, et al. Long-Term Outcomes of a Therapist-Supported, Smartphone-Based Intervention for Elevated Symptoms of Depression and Anxiety: Quasiexperimental, Pre-Postintervention Study. JMIR mHealth and uHealth [Internet]. 2019 Aug 26 [cited 2021 Jun 7];7(8):e14284. Available from: https://mhealth.jmir.org/2019/8/e14284/

42. Goldin PR, Lindholm R, Ranta K, Hilgert O, Helteenvuori T, Raevuori A. Feasibility of a Therapist-Supported, Mobile Phone-Delivered Online Intervention for Depression: Longitudinal Observational Study. JMIR Form Res [Internet]. 2019 Jan 22;3(1):e11509. Available from: http://dx.doi.org/10.2196/11509

43. Beck AT. Cognitive therapy and the emotional disorders [Internet]. Vol. 356. Oxford, England: Penguin; 1976. Available from: https://psycnet.apa.org/fulltext/1976-28303-000.pdf

44. Jacobson NS, Martell CR, Dimidjian S. Behavioral activation treatment for depression: returning to contextual roots. Clinical Psychology: science and practice [Internet]. 2001;8(3):255. Available from: https://psycnet.apa.org/journals/cps/8/3/255/

45. Kabat-Zinn J. Wherever You Go, There You Are: Mindfulness Meditation In Everyday Life [Internet]. Hachette Books; 2009.304 p. Available from: https://play.google.com/store/books/details?id=cVCZAAAAQBAJ

46. Morgan D. Mindfulness-based cognitive therapy for depression: a new approach to preventing relapse. Psychother Res [Internet]. 2003 Mar;13(1):123-5. Available from: http://dx.doi.org/10.1080/713869628

47. Carney CE, Edinger JD, Kuchibhatla M, Lachowski AM, Bogouslavsky O, Krystal AD, et al. Cognitive Behavioral Insomnia Therapy for Those With Insomnia and Depression: A Randomized Controlled Clinical Trial. Sleep [Internet]. 2017 Apr 1;40(4). Available from: http://dx.doi.org/10.1093/sleep/zsx019

48. Sarris J, Logan AC, Akbaraly TN, Amminger GP, Balanzá-Martínez V, Freeman MP, et al. Nutritional medicine as mainstream in psychiatry. Lancet Psychiatry [Internet]. 2015 Mar;2(3):271-4. Available from: http://dx.doi.org/10.1016/S2215-0366(14)00051-0

49. Lehrer P, Vaschillo B, Zucker T, Graves J, Katsamanis M, Aviles M, et al. Protocol for Heart Rate Variability Biofeedback Training. Biofeedback Self Regul [Internet]. 2013 Sep 1 [cited 2021 Mar 8];41(3):98-109. Available from: https://meridian.allenpress.com/biofeedback/article/41/3/98/113424/Protocolfor-Heart-Rate-Variability-Biofeedback

50. Kroenke K, Spitzer RL, Williams JB. The PHQ-9: validity of a brief depression severity measure. J Gen Intern Med [Internet]. 2001 Sep;16(9):606-13. Available from: http://dx.doi.org/10.1046/j.1525-1497.2001.016009606.x

51. Kroenke K, Strine TW, Spitzer RL, Williams JBW, Berry JT, Mokdad AH. The PHQ-8 as a measure of current depression in the general population. J Affect Disord [Internet]. 2009 Apr;114(1-3):163-73. Available from: http://dx.doi.org/10.1016/j.jad.2008.06.026

52. Tierney N. naniar [Internet]. Github; 2021 [cited 2021 Jun 8]. Available from: https://github.com/njtierney/naniar

53. Enders CK. Multiple imputation as a flexible tool for missing data handling in clinical research. Behav Res Ther [Internet]. 2017 Nov;98:4-18. Available from: http://dx.doi.org/10.1016/j.brat.2016.11.008

54. Matta TH, Flournoy JC, Byrne ML. Making an unknown unknown a known unknown: Missing data in longitudinal neuroimaging studies. Dev Cogn Neurosci [Internet]. 2018 Oct;33:83-98. Available from: http://dx.doi.org/10.1016/j.dcn.2017.10.001

55. van Buuren S. Multivariate Imputation by Chained Equations [R package mice version 3.13.0] [Internet]. Comprehensive R Archive Network (CRAN); 2021 [cited 2021 Jun 8]. Available from: https://cran.r-project.org/web/packages/mice/index.html

56. Bates D. Ime4 [Internet]. Comprehensive R Archive Network (CRAN); 2021 [cited 2021 Jun 4]. Available from: https://cran.rproject.org/web/packages/Ime4/index.html

57. Magnusson A. glmmTMB [Internet]. Comprehensive R Archive Network (CRAN); 2020 [cited 2021 Jun 4]. Available from: https://cran.rproject.org/web/packages/glmmTMB/index.html

58. Raudenbush SW, Bryk AS. Hierarchical Linear Models: Applications and Data Analysis Methods [Internet]. SAGE; 2002.485 p. Available from: https://play.google.com/store/books/details?id=uyCVOCNGDLQC

59. Brown VA. An Introduction to Linear Mixed-Effects Modeling in R. Advances in Methods and Practices in Psychological Science [Internet]. 2021 Jan 1;4(1):2515245920960351. Available from: https://doi.org/10.1177/2515245920960351

60. Hoffman L, Stawski RS. Persons as Contexts: Evaluating Between-Person and Within-Person Effects in Longitudinal Analysis. Res Hum Dev [Internet]. 2009 Jun 5;6(2-3):97-120. Available from: https://doi.org/10.1080/15427600902911189

61. Patil I. ggstatsplot [Internet]. Github; 2021 [cited 2021 Jun 1]. Available from: https://github.com/IndrajeetPatil/ggstatsplot 
62. Kassambara A. rstatix [Internet]. Comprehensive R Archive Network (CRAN); 2021 [cited 2021 Jun 7]. Available from: https://CRAN.Rproject.org/package=rstatix

63. Holm S. A Simple Sequentially Rejective Multiple Test Procedure. Scand Stat Theory Appl [Internet]. 1979;6(2):65-70. Available from: http://www.jstor.org/stable/4615733

64. Dennis M, Baillon S, Brugha T, Lindesay J, Stewart R, Meltzer H. The spectrum of suicidal ideation in Great Britain: comparisons across a 16-74 years age range. Psychol Med [Internet]. 2007 Jun;37(6):795-805. Available from: http://dx.doi.org/10.1017/S0033291707000013

65. Bruijniks SJE, Lemmens LHJ, Hollon SD, Peeters FPM, Cuijpers P, Arntz A, et al. The effects of once- versus twice-weekly sessions on psychotherapy outcomes in depressed patients. Br J Psychiatry [Internet]. 2020 Apr [cited 2021 Jun 4];216(4):222-30. Available from:

https://www.cambridge.org/core/journals/the-british-journal-of-psychiatry/article/effects-of-once-versus-twiceweekly-sessions-on-psychotherapyoutcomes-in-depressed-patients/C43C681866F3663A5C55BAFA2A99B8CB

66. Posner K, Brown GK, Stanley B, Brent DA, Yershova KV, Oquendo MA, et al. The Columbia-Suicide Severity Rating Scale: Initial Validity and Internal Consistency Findings From Three Multisite Studies With Adolescents and Adults. AJP [Internet]. 2011 Dec 1;168(12):1266-77. Available from: https://doi.org/10.1176/appi.ajp.2011.10111704

67. Posner K, Brent D, Lucas C, Gould M, Stanley B, Brown G, et al. Columbia-suicide severity rating scale (C-SSRS). New York, NY: Columbia University Medical Center [Internet]. 2008;10. Available from: https://vtspc.org/wp-content/uploads/2016/12/C-SSRS-LifetimeRecent-Clinical.pdf

\section{Figures}

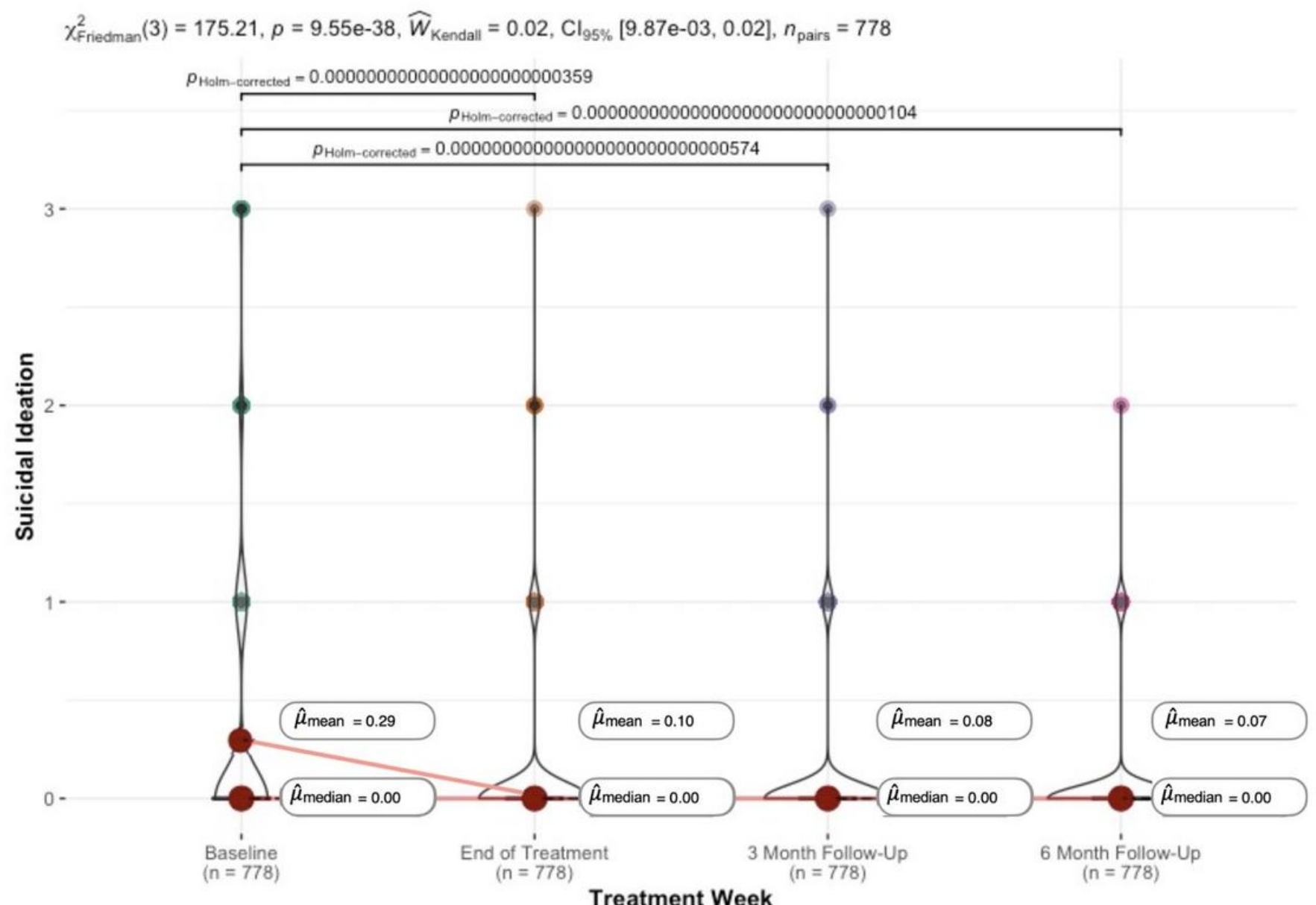

Pairwise test: Durbin-Conover test; Comparisons shown: only significant

\section{Figure 1}

Suicidal Ideation Over the Course of Treatment and Through Follow-up

NOTES: Suicidal ideation over the last 2 weeks is measured by the ninth item of the Patient Health Questionnaire-9 item (PHQ-9), with $0=$ not at all, $1=$ several days, $2=$ more than half the days, and $3=$ nearly every day. Non-significant Wilcoxon Test comparisons for changes in suicidal ideation are not shown. That is, there were no significant differences between end-of-treatment and 3-month follow-up, between end-of-treatment and 6-month follow-up, or between 3-month and 6-month follow-up. 
PHQ-9 Trajectory Across Treatment

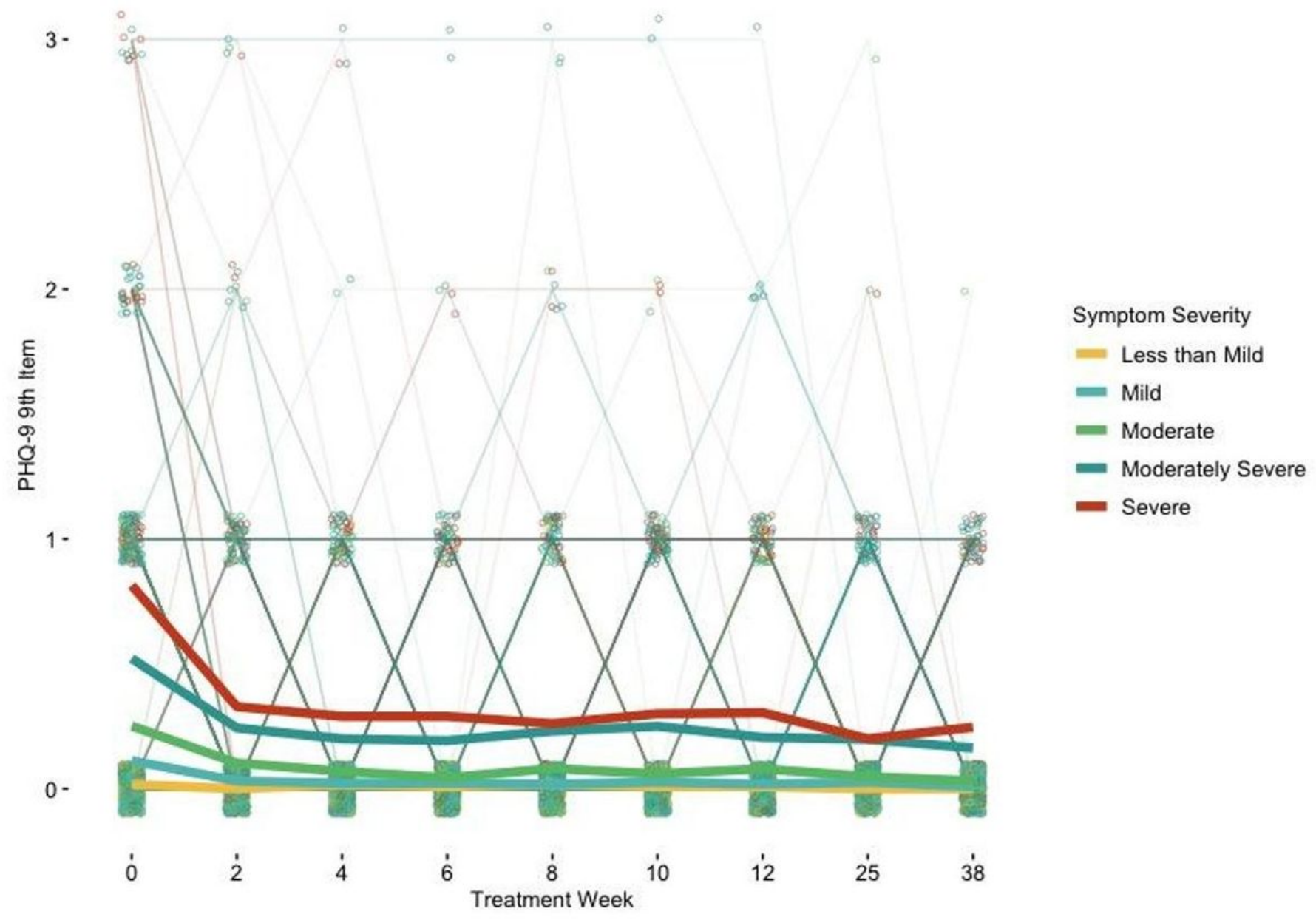

Figure 2

Suicidal Ideation over Treatment and Follow-up Week by Baseline Depressive Symptom Severity

NOTES: Suicidal ideation over the last 2 weeks is measured by the ninth item of the Patient Health Questionnaire-9 item (PHQ-9), with $0=$ not at all, $1=$ several days, $2=$ more than half the days, and $3=$ nearly every day. Treatment week 0 is the pre-treatment (baseline) assessment. Treatment week 12 is the end-oftreatment assessment. Treatment week 25 is the 3-month follow-up assessment. Treatment week 38 is the 6-month follow-up assessment. Symptom severity is measured by baseline PHQ-8 score as follows: less than mild=0-4, mild=5-9, moderate=10-14, moderately severe=15-19, severe=20+. Light lines are individual trajectories and dark lines are pre-treatment symptom severity group trajectories.

\section{Supplementary Files}

This is a list of supplementary files associated with this preprint. Click to download.

- SuicideMHPSupplementalMaterialsSubmittedBMCPsychiatry.docx 